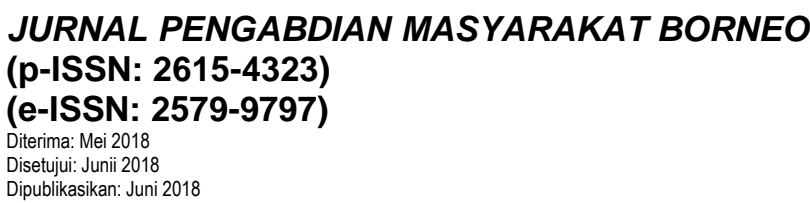

\title{
PEMBERDAYAAN MASYARAKAT DESA LONG BILA DAN DESA PULAU SAPI KABUPATEN MALINAU MELALUI OPTIMALISASI POTENSI LOKAL MELALUI REVOLUSI MENTAL MEWUJUDKAN DESA MANDIRI DAN MELAYANI
}

The Empowerment Community Long Bila Village And Pulau Sapi Village At Malinau Distric Through Optimization Of Local Potential Mental Revolution For Embodies The Independent And Serve Village

\author{
Endik Deni Nugroho ${ }^{1}$, Vlorensius ${ }^{2}$ \\ Fakultas Keguruan dan Ilmu Pendidikan, Universitas Borneo Tarakan \\ Jl. Amal Lama No.1, Tarakan KAL-TARA \\ Email: endwi.2011@gmail.com
}

\begin{abstract}
ABSTRAK
Kabupaten Malinau ditetapkan sebagai Kabupaten Konservasi di Kalimantan Utara, namun belum ada integrasi upaya konservasi dan pemanfaatan secara lestari atas sumber daya alam yang dimiliki. Salah satu program yang diterapkan oleh pemerintah Malinau yaitu Gerdema. Program ini merupakan pembangunan milik rakyat dengan agenda pemulihan ekonomi nasional yang berpihak pada masyarakat dalam mewujudkan kesejahteraan rakyat secara nyata. Program tersebut menuju ke arah pemberdayaan masyarakat desa yang kurang berkembang dalam model pembangunan, yang dilakukan secara terpadu, sinergis dan partisipatif dengan memanfaatkan sumberdaya potensi lokal tingkatan bawah seperti kepala desa sampai pemerintah kabupaten. Program kemintraan masyarakat (PKM) bertema Revolusi Mental dengan gerakan Indonesia Melayani dan Gerakan Indonesia Mandiri dapat membantu pemerintah desa dan Masyarakat. Metode yang digunakan dalam penelitian ini adalah metode parsipatoris. PKM berbasis revolusi mental dengan gerakan Indonesia melayani terfokus pada perbaikan administrasi dan peningkatan kualitas Sumber daya Manusia dan keterbukaan akses informasi publik, kegiatan tersebut mengandung nilai-nilai strategis instrumental revolusi mental yaitu Integritas dan Etos Kerja. Sedangkan gerakan Indonesia mandiri terfokus pada pada pemanfaatan potensi sumber daya alam daerah tertinggal, Mendukung dan mendorong kewirausahaan serta ekonomi kreatif memberdaakan potensi lokal menjadi ekowisata, Sosialisasi produk-produk dalam negeri yang berpotensi untuk dikembangkan. Berdasarkan hasil data masih banyak masyarakat dan perangkat desa yang menggunakan puas dan memahami gerakan revolusi mental Indonesia bersih sebanyak $90 \%$.
\end{abstract}

Kata Kunci: pemberdayaan masyarakat, potensi lokal, revolusi mental, desa mandiri, desa melayani

\begin{abstract}
Malinau is designated a Conservation District in North Kalimantan, but there is no integration of conservation and sustainable use of natural resources. One of the programs implemented by the Malinau government is Gerdema. This program is a development of the people with a national economic recovery agenda that sides with the community in realizing the welfare of the people in real. The program leads to the empowerment of less developed village communities in the development model, which is carried out in an integrated, synergistic and participatory manner by utilizing local potential resources of lower levels such as village heads to district governments. PKM themed Mental Revolution with the movement of Indonesia Serving and Indonesia independent Movement can help village government and Society. PKMbased mental revolution with the Indonesian movement serving focused on improving administration and quality improvement of Human Resources and openness of public information access, the activity contains the instrumental strategic values of mental revolution based on Integrity and Work Ethic. While the independent Indonesian movement focuses on the utilization of the natural resources potential of underdeveloped regions, Support and encourage entrepreneurship and creative economy to provide local potentials into ecotourism, socialization of domestic products that have the potential to be developed.
\end{abstract}

Endik D. N., Vlorensius., Pemberdayaan Masyarakat Desa...

Available at http://jurnal.borneo.ac.id/index.php/jpmb 
Based on the data results, there are still many people and village apparatus that use satisfied and understand the movement of mental revolution of Indonesia clean as much as $90 \%$.

Key Words: community empowerment, local potential, mental revolution, independent village, serving village

\section{PENDAHULUAN}

Kabupaten Malinau merupakan kawasan perhuluan sungai-sungai besar di wilayah propinsi Kalimantan Utara. Luas kawasan hutan di wilayah ini mencapai 3,9 juta Ha (90 \%), dimana hampir $50 \%$ dari kawasan hutan adalah kawasan Taman Nasional Kayan Mentarang dan hutan lindung. Sedangkan menurut RTRWK terbagi menjadi Kawasan Lindung 2,027,666 Ha, Kawasan Budidaya Kehutanan 1,980,510 dan kawasan budidaya kehutanan seluas 261,902 Ha. (Pemkab Malinau, 2015). Oleh karena potensi tersebut, maka Kabupaten Malinau ditetapkan sebagai Kabupaten Konservasi di Kalimantan Utara.

Masyarakat Kabupaten Malinau belum merasakan dampak ekonomi dari ditetapkannya Malinau sebagai Kabupaten Konservasi, dari hasil identifikasi Pusat Pengabdian Kepada Masyarakat Universitas Borneo Tarakan, menunjukkan bahwa kabupaten konservasi merupakan salah satu konsep yang diharapkan dapat mengatasi permasalahan lingkungan, namun tidak memberikan dampak ekonomi dan kesejahteraan masyarakat secara langsung (PPM 2014). Oleh karena itu, diperlukan adanya integrasi dari upaya konservasi dan pemanfaatan secara lestari atas sumber daya alam yang dimiliki misalnya dengan pemanfaatan hasil hutan nir kayu dan ekowisata.

Selain permasalahan kebijakan, pemerintah ingin membuat program bermunculan permeberdayaan masyarakat setiap tahunnya baik dari pemerintah pusat maupun daerah yang bertujuan untuk mendorong dan membangkitkan kemampuan masyarakat terutama masyarakat pedesaan. Programprogram tersebut bertujuan mewujudkan pemberdayaan yang perlu memunculkan kembali kearifan lokal, nilai-nilai, dan modal sosial yang dari dahulu memang sudah dianut oleh leluhur kita yang tinggal dipedesaan dalam "Integritas, etos kerja, dan gotong-royong" yang saat ini sudah mulai pudar dan mulai terkikis. Oleh sebab itu Pemerintah Kabupaten Malinau mengadakan program yang bernama Gerakan Desa Membangun (GERDEMA) yang dimana program tersebut menuju ke arah pemberdayaan masyarakat desa yang kurang berkembang dalam model pembangunan, yang dilakukan secara terpadu, sinergis dan partisipatif dengan memanfaatkan sumberdaya potensi lokal tingkatan bawah seperti kepala desa sampai pemerintah kabupaten.

Menurut Efendi (2014), Efendi (2004) menyatakan bahwa konsep pembangunan Kabupaten Malinau yang saat ini dengan Pola Program Gerakan Desa Membangun (Gerdema) perlu 
ditempatkan dalam tatanan pemberdayaan masyarakat secara luas. Melalui program Gerdema merupakan pembangunan milik rakyat dengan agenda pemulihan ekonomi nasional yang berpihak pada masyarakat dalam mewujudkan kesejahteraan rakayat secara nyata. Program Gerakan Desa Membangun (Gerdema) sejalan dengan nawacita presiden yaitu Revolusi mental. Dimana Revolusi Mental yang meliputi gerakan Indonesia Melayani, Indonesia Bersih, Indonesia tertib, Indonesia Mandiri, Indonesia Bersatu diharapkan Permasalahan yang ada di provinsi Kalimantan Utara sebagai Provinsi baru yaitu salah satunya membangun desa, termasuk pelayanan yang tersedia di kantor-kantor desa, dimana masyarakat berhak menerima akses pelayanan yang baik, cepat, dan mendapatkan akses informasi publik yang baik juga. Dan gerakan Indonesia Mandiri dengan memberdayakan masyarakat untuk membangun ekonomi kreatif dan membangun usaha milik desa yang bermanfaat untuk kesejahteraan masyarakat. Selama ini birokrasi yang ada masih bersifat klasik dan manual dan kurangnya akses pelayanan usaha kemasyarakatan dan akses informasi publik bagi masyarakat sehingga berdampak pada kepuasan masyarakat terhadap pelayanan publik berkurang. Dengan adanya pembangunan birokrasi desa melalui Indonesia Melayani demi mewujudkan masyarakat berintegritas dan berkarakter.

Sejalan dengan semakin meningkatnya kesadaran rakyat terhadap tepatnya strategi pembangunan desa yang dilakukan melalui Gerakan Desa
Membangun (GERDEMA) dengan semakin nyatanya kemajuan yang telah dicapai, tuntutan dan kepentingan masyarakat juga semakin meningkat. Berharap dengan adanya Program kemintraan masyarakat (PKM) bertema Revolusi Mental dengan gerakan Indonesia Melayani dan Gerakan Indonesia Mandiri dapat membantu pemerintah desa dan Masyarakat. Program kemintraan masyarakat merupakan sebuah media yang efektif dan edukatif, yaitu dosen bersama mahasiswa ke tengah-tengah masyarakat, meraka akan dapat menangkap dan menghayati denyut nadi kehudupan masyarakat. Persoalanpersoalan yang dihadapi, sumber-sumber daya yang telah dan belum dimiliki, dan solusi-solusi yang diperlukan sesuai dengan aspirasi dan harapan yang diimpikan masyarakat.

\section{METODE PELAKSANAAN}

Metode Pelaksanaan kegiatan Program kemintraan masyarakat (PKM) terbagi dalam beberapa tahap sebagai berikut :

\section{a. Persiapan}

1. PKM ini melibatkan mahasiswa dengan kegiatan wawancara untuk menjaring mahasiswa yang benar-benar komitmen terhadap program PKM yang ditawarkan, karena perlu keseriusan terlebih bhakti mahasiswa kepada masyarakat.

2. Materi sosialisasi PKM adalah sosial budaya, pemberdayaan Pendidikan, Pemberdayaan Kesehatan Masyarakat, wawasan revolusi mental, bidang administrasi baik administrasi negara maupun hukum administrasi dan teknik. 
3. Survei/Observasi ke lokasi, mitra dan kelompok masyarakat yang dijadikan sasaran PKM.yaitu di Malinau Barat di Desa Long Bila dan Kecamatan Mentarang di Desa Pulau Sapi.

4. Mengkomunikasikan program PKM dengan pemerintah daerah setempat, serta mitra lainnya dengan cara sosialisasi dan pendampingan kepada masyarakat.

5. Membuat persetujuan dari kesepakatan kerjasama dengan Badan Pemberdayaan Masyarakat Desa (BPMD) Kabupaten Malinau.

\section{b. Pelaksanaan Pengabdian Kepada Masyarakat (PKM)}

Kegiatan akan dilaksanakan menggunakan metode partisipatoris. Jadi, pelaksanaan program dilakukan dengan melibatkan masyarakat setempat dan mahasiswa Kuliah Kerja Nyata sebagai fasilitator. Untuk itu, diperlukan pendampingan dalam setiap kegiatan agar dapat diketahui dinamika dari kegiata tersebut sehingga dapat mewujudkan tujuan pemberdayaan. Adapun kegiatan yang di rancang adalah:

1. Bimbingan

teknis/Pendampingan/Penyuluhan

berupa aktivitas kegiatan Pertanian mahasiswa bersama masyarakat;

2. Aktivitas pendukung lainnya dalam rangka mengembangkan Kesadaran kebersihan, kesehatan dan lingkunga serta nasionalisme dengan program Gerakan Indonesia melayani dan Gerakan Indonesia Mandiri.

Program ini diharapkan dapat dijadikan rekomendasi untuk pemerintah akan potensi yang dimiliki daerah
Kalimantan Utara, sehingga dapat membantu dalam pengelolaan potensi tersebut. Keberlanjutan program perlu di komunikasikan dengan pihak BPMD Se Kalimantan Utara, sehingga dapat dilakukan secara luas dengan melibatkan Tim LPPM-selaku penyelenggara PKM Universitas Borneo Tarakan dalam setiap kegiatan pelatihan dan pendampingan. Selain itu, tindak lanjut program yang berhubungan dengan pengelolaan program dilakukan dengan mengoptimalkan peran BPMD Malinau untuk mendukung keberlanjutan usaha yang dikembangkan, serta lokasi akan diusulkan sebagai Desa Binaan Universitas Borneo Tarakan.

\section{HASIL PENELITIAN}

\section{A. Kegiatan Revolusi Mental Gerakan Indonesia Melayani}

Revolusi mental dengan Gerakan Indonesia Melayani (GIM) adalah gerakan para penyelenggara negara dan masyarakat untuk meningkatkan perilakupelayanan publik berintegritas agar negara hadir melindungi kepentingan warganya sesuai dengan Pancasila dan UUD 1945. GIM merupakan gerakan yang berawal dari permasalahan masyarakat Indonesia dalam aspek pelayanan publik yang dinilai belum dapat memberikan pelayanan yang memuaskan kepada masyarakat sehingga mutu pelayanan yang disediakan pemerintah perlu ditingkatkan untuk menjadi lebih baik. Oleh karena itu, dengan adanya GIM diharapkan terjadi peningkatan pelayanan public pada setiap instansi terutama yang mempunyai tugas utama melakukan pelayanan umum. 
Seperti halnya kegiatan pengabdian masyarakat yang dilakukan pada desa Long Bilad dan Desa Pulau Sapi dimana kegiatan meliputi membantu memperbaiki dan penguatan kualitas SDM Aparat desa dalam pelayanan masyarakat, Keterbukaan informasi publik yang jelas dan tegas terkait pelayanan umum, seperti informasi kepada masyarakat terkait informasi pengurusan pengurusan administrasi pembuatan KTP, pembuatan BPJS, pengurusan akte kelahiran, pengurusan Kartu Keluarga Serta Pengurusan Surat Tanah.
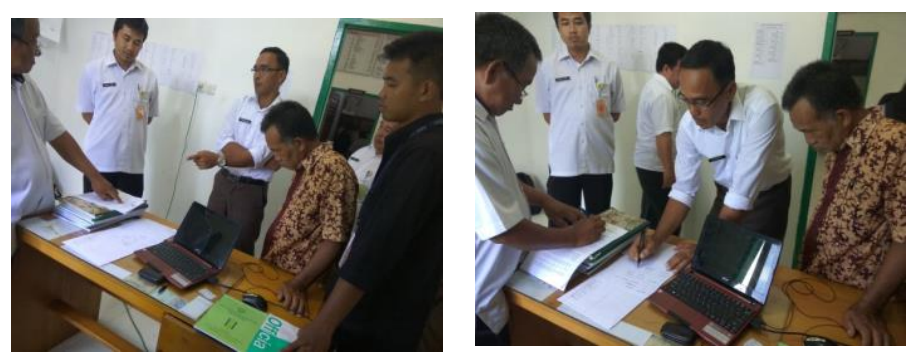

Gambar 1. Kegiatan Pendampingan Gerakan Indonesia Melayani, Memperbaiki Administrasi Desa
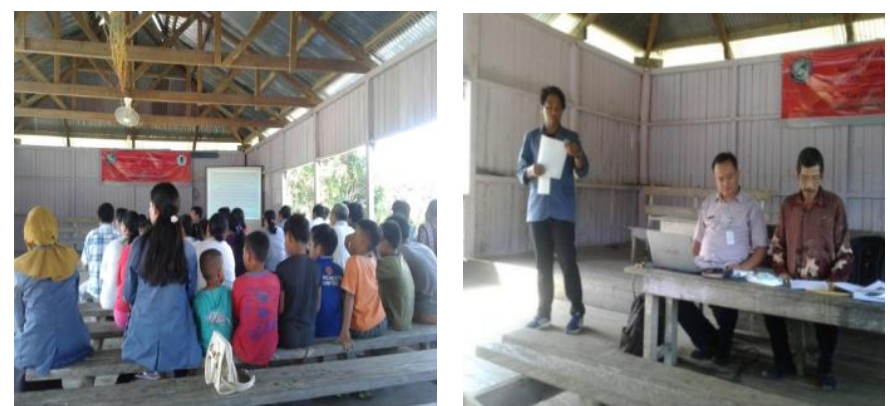

Gambar 2. Kegiatan Sosialisasi Pelayanan Pendidikan wajib Sejak Dini
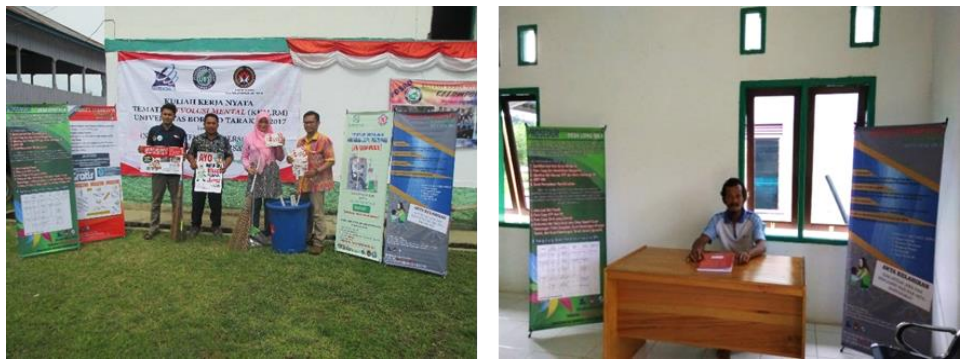

Gambar 3. Memberikan Stand Banner Pelayanan Publik terkait, BPJS, Prosedur Akta Kelahiran
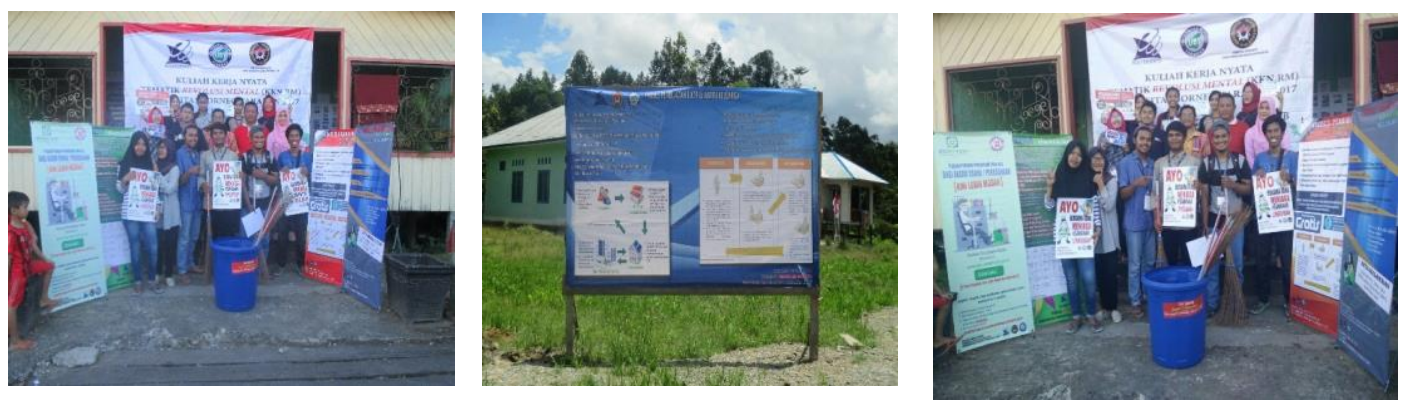

Gambar 4. Memberikan Stand Banner Pelayanan Publik terkait, BPJS, Prosedur Akta Kelahiran, Pengurusan Sertifikat tanah, dan Pembuatan kartu keluarga

Endik D. N., Vlorensius., Pemberdayaan Masyarakat Desa... 
Pada program revolusi mental dengan gerakan Indonesia melayani di desa Long Bila Kecamatan Malinau Barat dan Desa Pulau Sapi Kecamatan Mentarang, Kabupaten Malinau terfokus pada tingkat kesadaran masyarakat terhadap akses pelayanan publik baik perangkat desa maupun masyarakat sekitar. Berdasarkan data kepuasan dan pemahaman gerakan revolusi mental Indonesia melayani, masyarakat sangat terbantu dan memperoleh manfaat dari gerakan Indonesia Melayani yang merupakan bagian dari aksi revolusi mental. Berdasarkan data kepuasan dan pemahaman gerakan revolusi mental Indonesia bersih, maka kemudian dilakukan wawancara kepada masyarakat dan perangkat desa hasilnya masyarakat puas dan sudah memahami gerakan revolusi mental Indonesia melayan. Wawancara berisi tentang metode yang dominan dilakukan oleh masyarakat dan perangkat desa yang terlibat. Berdasarkan hasil data masih banyak masyarakat dan perangkat desa yang menggunakan puas dan memahami gerakan revolusi mental Indonesia bersih sebanyak 90\%. Dari Kegiatan tersebut perlunya tindak lanjut dan kegiatan yang berkesinambungan, agar masyarakat dapat merasakan dampak dan manfaat yang massif serta menyeluruh disetiap masyarakat.

Gerakan Indonesia Melayani (GIM) dalam aksi revolusi mental ini selain memberikan manfaat kepada masyarakat, dan juga memuat nilai- nilai strategis instrumental revolusi mental yaitu Integritas dan Etos Kerja. Gerakan Indonesia Melayani memuat nilai Integritas, dimana nilai tersebut merupakan kesatuan kata dan perbuatan yang mengarahkan karakter dan perilaku seseorang secara bertanggung jawab. Bentuk penjabaran nilai integritas antara lain dapat dipercaya, sadar hak dan kewajiban, serta bertanggungjawab melalui media informasi publik. Selain itu Gerakan Indonesia Melayani (GIM) adalah tersedianya SOP pelayanan publik prima yang langsung berhubungan dengan masyarakat yang meliputi: Perubahan Sistem: yaitu Kejelasan, kemudahan, dan keterbukaan informasi mengenai prosedur layanan; Memiliki tenggat waktu yang pasti dalam merespon dan mengandung nilai Etos Kerja yaitu semangat kerja yang menjadi ciri khas dan keyakinan seseorang atau masyarakat. Etos kerja seseorang berkaitan erat dengan kepribadian, perilaku, dan karakter individu yang bersangkutan.

\section{B. Kegiatan Revolusi Mental Gerakan Indonesia Mandiri}

Gerakan Indonesia Mandiri (GIMa) adalah gerakan para Penyelenggara Negara dan masyarakat untuk mendorong budaya kreatif, inovatif, dan beretos kerja tinggi untuk meningkatkan produktivitas dan daya saing bangsa. Gerakan ini akan mendorong terwujudnya kemandirian dalam berbagai sektor kehidupan, seperti 
pertumbuhan kewirausahaan dan ekonomi kreatif, peningkatan UMKM dan koperasi, peningkatan apresiasi seni, kreativitas karya budaya dan warisan budaya. Peningkatan kemandirian terutama nilai etos kerja merupakan faktor strategis dalam menghadapi persaingan regional dan global. Gerakan ini dilakukan oleh para penyelenggara negara dan masyarakat yang saling bersinergi untuk mewujudkan kemandirian bangsa di berbagai sektor kehidupan.

Seperti halnya kegiatan pengabdian masyarakat yang dilakukan di desa Long Bilad dan Desa Pulau Sapi dimana kegiatan Gerakan Indonesia Mandiri meliputi membuat Membudayakan perilaku mandiri, Mendukung dan mendorong kewirausahaan serta ekonomi kreatif memberdaakan potensi lokal menjadi ekowisata,

Melakukan pengembangan teknologi tepat guna untuk mendorong ekonomi kreatif, Melakukan identifikasi dan pemanfaatan potensi sumber daya alam daerah tertinggal, dan Melakukan pelatihan SDM untuk aktivitas ekonomi kreatif. Harapan dengan adanya kegiatan Gerakan Indonesia Mandiri di desa Long Bila dan Desa Pulau Sapi Mewujudkan Indonesia yang berdaulat secara politik, mandiri secara ekonomi, dan berkepribadian yang kuat melalui pembentukan manusia Indonesia baru yang unggul menerapkan nilainilai integritas, kerja keras, dan semangat gotong royong.
Gerakan Indonesia Mandiri, adalah gerakan untuk mewujudkan perilaku kreatif, inovatif, dan beretos kerja tinggi agar mewujudkan kemandirian dibidang pangan, energi, dan teknologi dalam menghadapi persaingan regional dan global. Gerakan Indonesia Mandiri di desa Long Bila dan Desa Pulau Sapi kecamatan mentarang terfokus pada Mendukung dan mendorong kewirausahaan serta ekonomi kreatif memberdayakan potensi lokal menjadi ekowisata, dan Sosialisasi produk-produk dalam negeri yang berpotensi untuk dikembangkan. Dalam Pelaksanaan Gerakan Indonesia Mandiri mengandung nilai instrumental revolusi mental yaitu nilai Etos kerja dan Gotong Royong. Dimana nilai etos kerja merupakan semangat kerja yang menjadi ciri khas dan keyakinan seseorang atau masyarakat desa Pulau Sapi dengan memberdayakan potensi lokal masyarakat meningkatkan nilai daya saing, kreatif, mandiri, inovatif dan produktif sehingga mewujudkan, mendorong, mendukung, dan meningkatkan kewirausahaan, serta ekonomi kreatif masyarakat desa. Sedangkan nilai Gotong royong merupakan nilai yang telah ada sejak zaman nenek moyang kita. Masyarakat Indonesia dikenal sejak lama telah menggunakan cara kerjasama di dalam menyelesaikan setiap masalah yang mereka hadapi. Bentuk nilai gotong royong antara lain terdiri dari salingmenghargai, kerjasama, solidaritas, perilaku tolong menolong, berorientasi pada 
kebaikan Bersama. Diharapkan Melalui gerakan Indonesia mandiri PKM berbasis Revolusi Mental Universitas Borneo Tarakan mendorong, mendukung, dan meningkatkan kewirausahaan, serta ekonomi kreatif masyarakat desa.

Saran dalam pelaksanaan kegiatan Program Kemitraan Masyarakat berbasis Revolusi mental dengan gerakan Indonesia melayani dan Gerakan Indonesia mandiri Kecamatan malinau barat di Desa
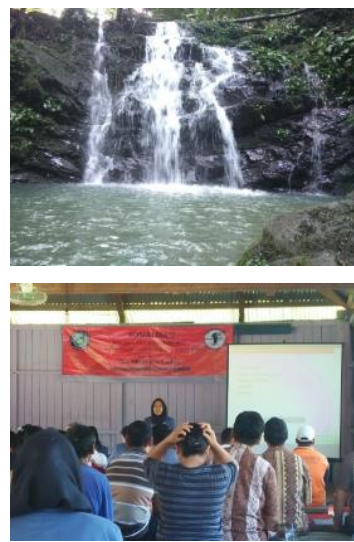

Gambar 5. Menemukan Sumber Potensi Lokal Berupa Air Terjun dan Mendorong untuk dijadikan Peluang Ekowisata melalui sosialisasi bumdes Ekowisata
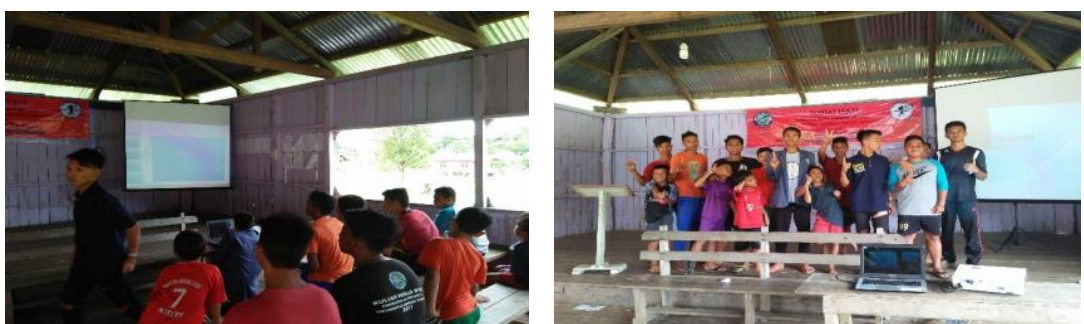

Gambar 6. Memberikan pembekalan anak remaja terkait pemandu wisata dan sosialisasi Promosi Ekoisata
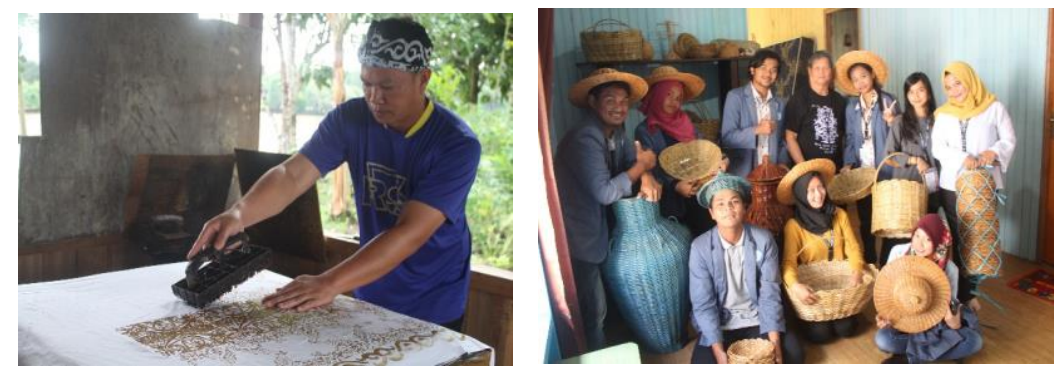

Gambar 7. Sosialisasi produk-produk lokal dalam negeri yang berpotensi untuk dikembangkan

Endik D. N., Vlorensius., Pemberdayaan Masyarakat Desa...

Available at http://jurnal.borneo.ac.id/index.php/jpmb 


\section{KESIMPULAN}

Kegiatan Program Kemitraan

Masyarakat (PKM) berbasis Revolusi mental dengan gerakan Indonesia Melayani dan Gerakan Indonesia mandiri Kecamatan Malinau Barat di Desa Long Bila dan Kecamatan Mentarang di Desa Pulau Sapi berjalan dengan baik. PKM berbasis revolusi mental dengan gerakan Indonesia melayani terfokus pada perbaikan administrasi dan peningkatan kualitas Sumber daya Manusia dan keterbukaan akses informasi public, kegiatan tersebut mengandung nilai-nilai strategis instrumental revolusi mental yaitu Integritas dan Etos Kerja. Sedangkan gerakan Indonesia mandiri terfokus pada pada pemanfaatan potensi sumber daya alam daerah tertinggal, Mendukung dan mendorong kewirausahaan serta ekonomi kreatif memberdaakan potensi lokal menjadi ekowisata, Sosialisasi produkproduk dalam negeri yang berpotensi untuk dikembangkan dan melakukan pengembangan teknologi tepat guna untuk mendorong ekonomi kreatif, gerakan Indonesia Mandiri mengandung nilai instrumental revolusi mental yaitu nilai Etos kerja dan Gotong Royong.

\section{DAFTAR PUSTAKA}

Efendi. 2014. Pelaksanaan Program Gerakan Desa Membangun (Gerdema) Pada Bidang Perkebunan Di Desa Data Baru Kecamatan Sungai Boh Kabupaten Malinau. eJournal Ilmu Pemerintahan, 2014, 2 (1).

Sunda, Feri. 2015. Studi Tentang Pelaksanaan Gerakan Desa Membangun (Gerdema) Di Desa Long Ampung Kecamatan Kayan Selatan. eJournal Ilmu Pemerintahan, 3 (3).

Katalog Badan Pusat Statistik. 2017. Statistik Daerah Kecamatan Mentarang 2017. BPS. Kabupaten Malinau.

Katalog Badan Pusat Statistik. 2017. Statistik Daerah Kecamatan Malinau Barat 2017. BPS. Kabupaten Malinau. 